\title{
Cumbanam \\ Report of a Case of Peripheral Giant Cell Granuloma in Anterior Maxillary Region
}

\section{P Moeiny ${ }^{1}$, S Shabani ${ }^{\star 2}$, M Vatankhah $^{2}$, A bakhshi $^{3}$, M Zameni $^{4}$}

1-Assistant Prof, Pediatric Dentistry Dept,Tehran Medical Sciences, Tehran Medical Sciences, Islamic Azad University, Tehran, Iran,

2- Postgraduate Student, Pediatric Dentistry Dept,Tehran Medical Sciences, Islamic Azad University, Tehran, Iran,

3-Dentist, Vancouver, BC, Canada.

4- Postgraduate Student,Department of Oral and Maxillofacial Radiology,Tehran Medical Sciences,

Islamic Azad University, Tehran, Iran,

\begin{tabular}{|c|}
\hline INFO \\
\hline $\begin{array}{l}\text { Article History } \\
\text { Received: May } 2018 \\
\text { Accepted: Apr } 2018 \\
\text { ePublished: Jun } 2018\end{array}$ \\
\hline $\begin{array}{l}\text { Corresponding author: } \\
\text { S Shabani, } \\
\text { Postgraduate Student, } \\
\text { Pediatric Dentistry } \\
\text { Dept,Tehran Medical } \\
\text { Sciences, Islamic Aza } \\
\text { University, Tehran, } \\
\text { Iran, Email: sima. } \\
\text { sh8869@gmail.com }\end{array}$ \\
\hline
\end{tabular}

\section{Introduction:}

Reactive hyperplastic lesions comprise fibrous changes in the connective tissue. They are common tumor-like proliferations and are usually formed as a result of abnormal healing processes. ${ }^{(1)}$ The majority of these lesions are dis covered in young adults with a predilection for females. They usually appear in the oral mucosa in response to injuries such as local chronic irritation or trauma due to the presence of a foreign body, restorations with irregular margins, low-grade trauma or iatrogenic factors. ${ }^{(1)}$ Local hyperplasia is the reaction of the mucosa to these irritants and is composed of mature collagen, fi-

\begin{abstract}
Background and Aim: Gingival overgrowth is a common clinical finding that most often represents reactive hyperplasia as a result of inflammatory gingival disease related to dental plaque. Irritation fibroma (IF), pyogenic granuloma (PG), peripheral ossifying fibroma (POF), and peripheral giant cell granuloma (PGCG) are nonneoplastic enlargements of the gingiva that are categorized as reactive hyperplastic lesions. Most of these lesions have a similar clinical appearance, i.e., a sessile or All reactived nodule at the interdental papilla; the color varies from pale pink to red. duration, and histologic features.

Case Presentation: Here, we present a case of PGCG in a 10-year-old male with its clinical presentations as well as radiological and histological features along with the management procedure.

Conclusion: Choice of treatment for our case was surgical excision, fluoride therapy, and oral hygiene maintenance. The patient remained tumor-free for 18 months and is still on regular follow-up.

ant Cell Granuloma, Maxilla
\end{abstract}

\section{J Res Dent Maxillofac Sci 2019;4(1):26-30}

DOI: 10.29252/jrdms.4.1.41

broblasts, mineralized tissue, endothelial cells, and multinucleated giant cells. ${ }^{(1)}$

Neville classifies common gingival overgrowths under the following categories: (1) "pyogenic granuloma (PG; including pregnancy tumor), ${ }^{(2)}$ peripheral ossifying fibroma (POF; also referred to as ossifying fibroid epulis, peripheral fibroma with calcification, calcifying fibroblastic granuloma, and peripheral odontogenic ossifying fibroma), ${ }^{(3)}$ peripheral fibroma, also referred to as focal fibrous hyperplasia (FFH) and fibrous epulis, and ${ }^{(4)}$ peripheral giant cell granuloma (PGCG)". (2) 
PGCG is a common gingival overgrowth with uncertain pathogenicity. Similar to POF, local irritants are probably responsible for the occurrence of this lesion. Histologically, this lesion consists of "edematous, mitotically active, loose connective tissue proliferation, and numerous osteoclast-like multinuclear giant cells". ${ }^{(3)}$ In addition, hemosiderin accumulation with bleeding zones, numerous dilated vessels, chronic inflammatory cell infiltration, and bone formation may be present. ${ }^{(3)}$ Oral mucosal overgrowths, particularly PGCG and POF, share histological features such as abnormal connective tissue proliferation with varying amounts of giant cells and focal osteogenesis; $;^{(4)}$ however, PGCG is composed of relatively more immature and loose components compared to POF. In some cases, there may be confusion in the histologic differentiation of these lesions. It seems likely that POF may be a subsequent lesion with morphologically more mature components. It has also been proposed that some PGs may transform into POF in the late regression stage. ${ }^{(4)}$

There is a significant overlap among different histological entities of local inflammatory hyperplasia; however, it is unclear whether they characterize the same lesion at different developmental stages. The vascular component of PG may be partially or completely replaced by fibrous tissue and be diagnosed as PG or fibroma. It seems that the common location of gingival inflammatory hyperplasias supports the theory that they represent the same lesion at different phases of histological development. All reactive gingival lesions show some differences in terms of gender, type, location, duration, and histologic features. Some studies have stated that the definitive treatment comprises complete removal of local irritants with follow-up care as well as dental hygiene maintenance to avoid recurrence. ${ }^{(4,5)}$ Here, we report a case with histologic signs of PGCG after gaining the patient's consent.

\section{Case Presentation:}

A 10-year-old male presented with a complaint of a gingival mass in the anterior maxilla. A slowly enlarging gingival mass with a red sur- face was observed in the area of unerupted tooth \#23. The lesion was first noted three months ago, but recently, it was showing an increase in size. The patient had no history of cardiovascular diseases, allergies, systemic diseases, surgery, hospitalization, or drug consumption. The pulse rate, blood pressure, and respiratory rate were normal in physical examinations. The extraoral examination showed fading of the nasolabial fold on the left side without texture change, tenderness, paresthesia, hypoesthesia or fistula. The lymph nodes were normal under palpation. The temporomandibular joint (TMJ) and mouth opening range were normal with no clicking sounds.

The intraoral examination revealed an asymptomatic, round, and red-colored soft tissue lesion with a smooth surface. The lesion had a fibrous consistency, was firm to the touch, and was approximately $10 \mathrm{~mm}$ in its largest diameter. The lesion was located on the attached gingiva. The patient was in the mixed dentition stage with relatively poor oral hygiene (Figure 1). The panoramic radiograph of the patient's jaws showed no evidence of intrabony pathology in association with the soft tissue lesion (Figure 2).

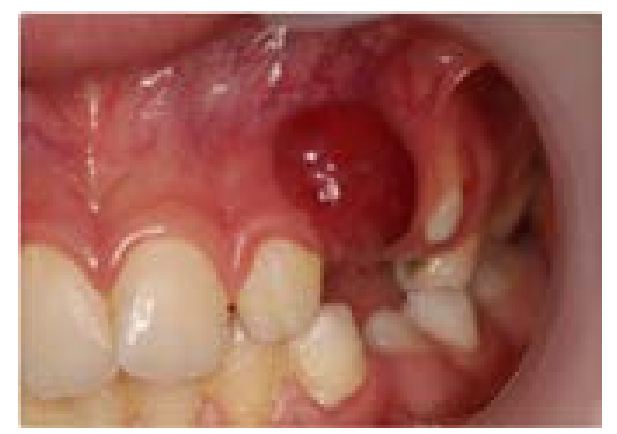

Figure 1. Clinical appearance of the lesion

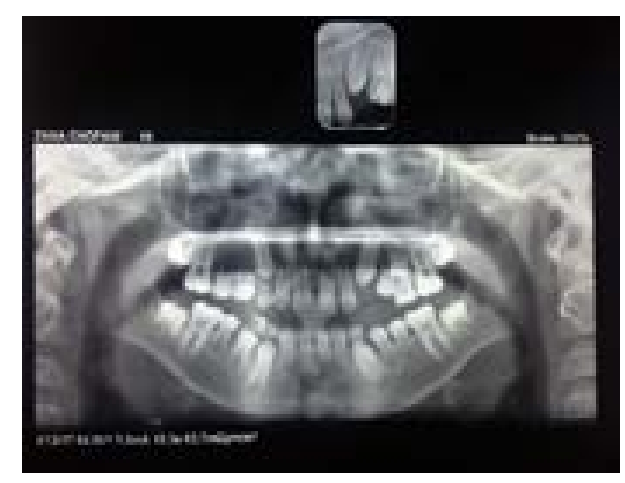

Figure 2. Panoramic radiograph of the patient 
After a complete examination, the differential diagnoses included PGCG, PG, irritation fibroma (IF), hemangioma, and POF. The patient was submitted to excisional biopsy, and the lesion was excised down to the periosteum using a \#15C blade and a surgical spoon-shaped curette. The specimen was sent for histopathological examination.

The microscopic sections revealed parakeratinized squamous epithelium of the oral mucosa. Multinucleated giant cells in a background of spindle-shaped mesenchymal cells, foci of reactive bone formation as well as mild to moderate chronic inflammatory cell infiltration were seen. Also, hemosiderin pigmentation and red blood cells (RBC) extravasation were seen in some areas. There was no evidence of malignancy in this specimen. The pathologic features of the lesion supported PGCG as the final diagnosis (Figures 3 and 4).

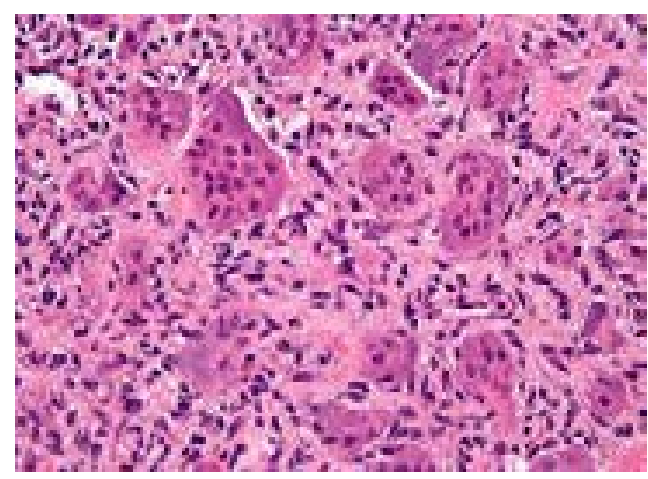

Figure 3. Multinucleated giant cells

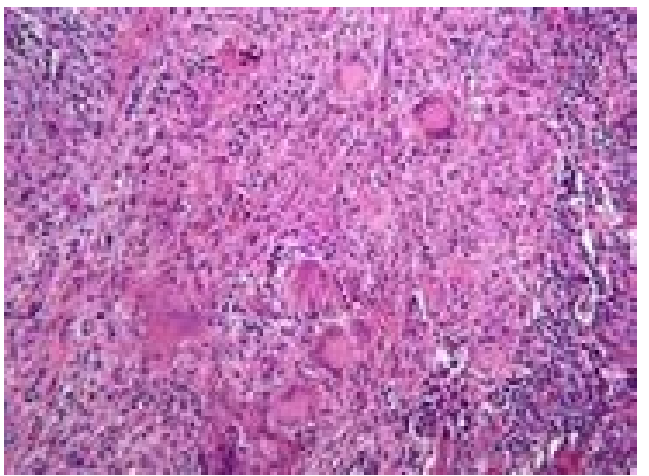

Figure 4. Parakeratinized squamous epithelium of the oral mucosa with multinucleated giant cells in a background of spindle-shaped mesenchymal cells
In the postoperative follow-up, the region showed proper wound healing. No signs of recurrence were observed during 6-month (Figure 5) and 18-month follow-ups (Figure 6).

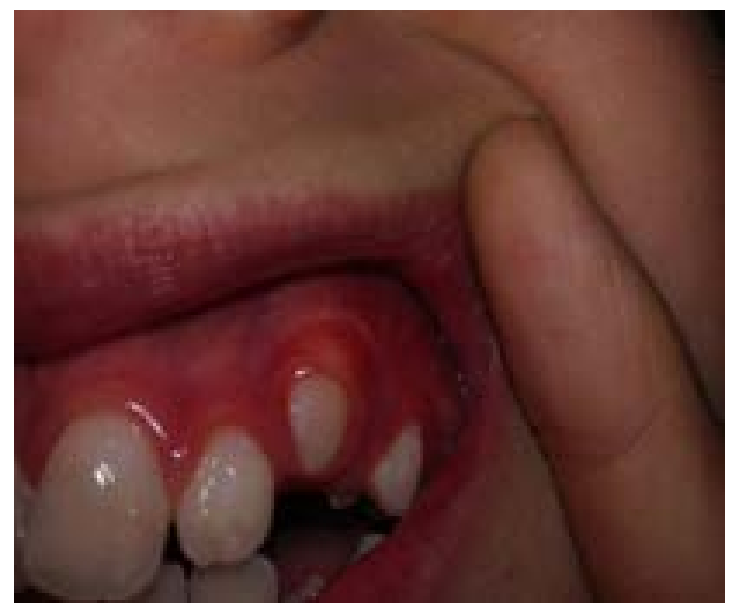

Figure 5. Photograph of the area after 6 months

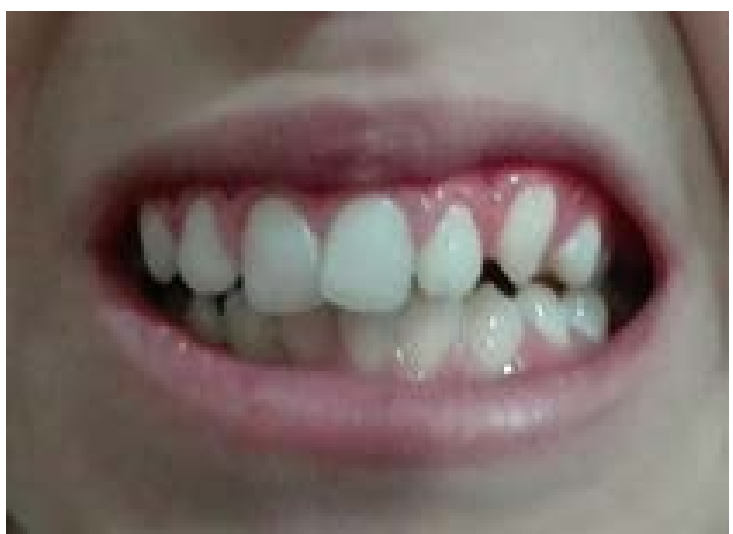

Figure 6. Photograph of the area after 18 months

\section{Discussion:}

IF, PG, POF, and PGCG are non-neoplastic enlargements of the gingiva that are classified as reactive hyperplastic lesions. ${ }^{(5)} \mathrm{POF}$ is a pedunculated or sessile nodule with a pink to a red surface, frequently ulcerated, firm, and non-tender, with limited growth potential, which may resorb the alveolar bone. It originates from the interdental papilla of the attached gingiva; the most common site is the anterior region of the jaws. It is composed of cellular fibroblastic tissue and mineralized components consisting of bone, cement-like materials or dystrophic calcifications. ${ }^{(6)}$ IF has a pink smooth surface, is firm and non-tender, and has limited growth potential. 
It is located on the buccal or labial mucosa, the tongue, or the attached gingiva and is composed of connective tissue with dense collagen. ${ }^{(7)} \mathrm{PG}$ has a smooth to an irregular red surface, is usually ulcerated, soft, and non-tender, with limited growth potential; it is most often located on the attached gingiva. Other sites include the lips, the tongue, and the buccal mucosa. It may also involve the skin. It is composed of hyperplastic granulation tissue with a noticeable proliferation of endothelial cells covering the capillary channels and an infiltrate of mixed inflammatory cells. ${ }^{(3)}$ PGCG

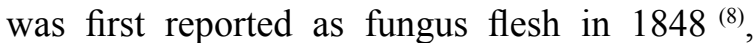
and later, it was reported as giant cell reparative granuloma by Jaffe in $1953 .{ }^{(9)}$ Following reports also featured a different terminology including osteoclastoma, giant cell epulis, and myeloid epulis. ${ }^{(10)}$ PGCG is now the preferred terminology. PGCG, with a red or a purple-blue surface, may be ulcerated, firm, and non-tender, with limited growth potential and may resorb the alveolar bone. It is attached to the gingiva or alveolar mucosa. It consists of multinucleated giant cells and mesenchymal cells with noticeable vascularization, abundant hemorrhage, and hemosiderin deposits at the lesion>s periphery. It can also present signs of chronic inflammation, areas of reactive bone, and even dystrophic calcifications. ${ }^{(3)}$ POF and PGCG are site-specific lesions arising exclusively from the periodontal ligament (PDL); this makes both lesions related to the gingiva and alveolar ridge. ${ }^{(11,13)}$ Their histogenesis is distinct from that of their intraosseous counterparts, i.e., central ossifying fibroma (COF) and central giant cell granuloma (CGCG), which are intrabony benign neoplasms of the jawbone. ${ }^{(12)}$ Thus, POF and PGCG are regarded as reactive lesions of the gingiva, often presenting as painless, lobular, and ulcerated masses that are clinically indistinguishable from one another. Ogbureke and colleagues reported a case of PGCG with extensive osseous metaplasia or a hybrid PGCG-POF. ${ }^{(14)}$ Their presentation of this lesion, consisting of areas of PGCG as well as a distinct area of extensive bone formation, is reminiscent of POF and explains its consideration as a hybrid lesion. (14) Although the biologic behavior of a hybrid lesion is not expected to differ significantly from that of either of the single entities, this case raises the question that whether PGCG and POF are parts of a disease spectrum or whether some of these lesions are true hybrid lesions; ${ }^{(14)}$ this case was similar to our presentation. Raizada and colleagues reviewed a case series of isolated gingival overgrowths. ${ }^{(15)}$ They stated that clinical differential diagnoses for localized gingival overgrowths include fibroma, PGCG, PG, peripheral odontogenic fibroma, and POF. ${ }^{(15)}$ A healthy oral environment will reduce local microflora and help eliminate the infection. ${ }^{(15)}$ We recommended surgical excision in addition to the above treatment for similar cases but Raizada et al did not recommend such treatment. ${ }^{(15)}$

\section{Conclusion:}

Choice of treatment for our case was surgical excision, fluoride therapy, and oral hygiene maintenance. The recovery was good, and the patient remained tumor-free for 18 months and is still on regular follow-up.

\section{References:}

1- Neville BW, Damm DD, Allen CM, Bouquot JE. Oral and Maxillofacial Pathology. St. Louis: Saunders/Elsevier; 2009:507-563.

2- Neville BW, Damm DD, Allen CM, Bouquot JE. Oral and Maxillofacial Pathology. Philadelphia: W.B. Saunders, 1995:517-20.

3- Salum FG, Yurgel LS, Cherubini K, De Figueiredo MA, Medeiros IC, Nicola FS. Pyogenic granuloma, peripheral giant cell granuloma and peripheral ossifying fibroma: retrospective analysis of 138 cases. Minerva Stomatol. 2008 May;57(5):227-32.

4- Prasad S, Reddy SB, Patil SR, Kalburgi NB, Puranik RS. Peripheral ossifying fibroma and pyogenic granuloma. Are they interrelated? N Y State Dent J. 2008 Mar;74(2):50-2.

5- Giansanti JS, Waldron CA. Peripheral giant cell granuloma: Review of 720 cases. J Oral Surg. 1969 Oct;27(10):787-91.

6- Patil KP, Kalele KP, Kanakdande VD. Peripheral giant cell granuloma: A comprehensive review of an ambiguous lesion. J Int Clin Dent Res Organ. 2014;6(2):118-25.

7- Macleod RI, Soames JV. Epulides: a clinicopathological study of a series of 200 consecutive lesions. Br Dent J. 1987 Jul 25;163(2):51-3.

8- Tomes J. A Course of Lectures on Dental Physiology and Surgery, delivered at the Middlesex Hospital School. Am J Dent Sci. 1848 Apr;8(3):209-246. 
9- Jaffe HL. Giant-cell reparative granuloma, traumatic bone cyst, and fibrous (fibro-osseous) dysplasia of the jawbones. Oral Surg Oral Med Oral Pathol. 1953 Jan;6(1):159-75.

10- Buchner A, Hansen LS. The histomorphologic spectrum of peripheral ossifying fibroma. Oral Surg Oral Med Oral Pathol. 1987 Apr;63(4):452-61.

11- Cawson RA, Binnie WH, Speight PM, Barrett AW, Wright JM. Lucas Pathology of Tumors of Oral Tissues. Missouri: Mosby, 1998:252-4. 12-Neville BW, Damm DD, Allen CM, Bouquot JE. Oral and Maxillofacial Pathology. Philadelphia: W.B. Saunders, 2008:485.

13-Sadri D, Farhadi S, Mohammadi M, Seyedpour SM. Frequency of technical errors in the biopsy samples submitted to an oral and maxillofacial pathology laboratory. J Res Dentomaxillofac Sci. 2017; 2 (2):29-33.

14- Ogbureke EI, Vigneswaran N, Seals M, Frey G, Johnson CD, Ogbureke KU. A peripheral giant cell granuloma with extensive osseous metaplasia or a hybrid peripheral giant cell granuloma-peripheral ossifying fibroma: a case report. J Med Case Rep. 2015 Feb 4;9:14.

15-Raizada S, Varghese JM, Bhat KM, Gupta $\mathrm{K}$. Isolated gingival overgrowths: A review of case series. Contemp Clin Dent. 2016 AprJun;7(2):265-8.

Please cite this paper as:

Moeiny P, Shabani S, Vatankhah M, Zameni M. Report of a Case of Peripheral Giant Cell Granuloma in Anterior Maxillary Region. J Res Den-

tomaxillofac Sci. 2019; 4 (1) :26-30 